\title{
Long-term health of children conceived after assisted reproductive technology
}

\author{
Christina Bergh ${ }^{\mathrm{a}, \mathrm{b}}$ and Ulla-Britt Wennerholm ${ }^{\mathrm{a}}$ \\ ${ }^{a}$ Department of Obstetrics and Gynecology, Institute of Clinical Sciences, Sahlgrenska Academy, Gothenburg University, Gothenburg, \\ Sweden; ${ }^{\text {b }}$ Reproductive Medicine, Sahlgrenska University Hospital, Gothenburg, Sweden
}

\section{ABSTRACT}

The aim of this narrative review is to summarize the present knowledge on long-term outcome of children born after assisted reproductive technologies (ART). The main outcomes covered are neurodevelopment including cerebral palsy, cognitive development, attention deficit hyperactivity disorder and autism spectrum disease, growth, cardiovascular function, diabetes type 1, asthma, malignancies, and reproductive health. Results have mainly been obtained from systematic reviews/meta-analyses and large registry studies. It has been shown that children born after ART, when restricted to singletons, have a similar outcome for many health conditions as their spontaneously conceived peers. For some outcomes, particularly cardiovascular function and diabetes, studies show some higher risk for ART singletons or subgroup of ART singletons. The fast introduction of new ART techniques emphasizes the importance of continuous surveillance of children born after ART.

\section{ARTICLE HISTORY}

Received 27 January 2020

Revised 8 February 2020

Accepted 11 February 2020

\section{KEYWORDS}

Assisted reproductive technology; long-term follow up; ICSI; IVF

\section{Introduction}

There are numerous publications on the short-term outcome after assisted reproductive technology (ART), including large registry studies and systematic reviews (SRs)/meta-analyses. Most of them reveal some adverse outcome also for singletons, particularly concerning preterm birth, low birth weight, and birth defects. Literature concerning long-term outcome is much more sparse. This is the case, despite the fact that large cohorts of ART children and adolescents now exist. While national birth registries, with extensive data on neonatal outcome, are present in several countries, this is not the case for children's health in general. To catch children/adolescence health, patient or specific disease registries may be used. These registries include, however, only those children with specific diseases, and most severe diseases occur later in life, leaving few events and low power of such studies. The following summary is based on large registry studies and SRs where such exist. Cohort studies with sometimes a limited number of children have been included as well. The following aspects will be discussed: neurodevelopment including cerebral palsy $(\mathrm{CP})$, cognitive development, attention deficit hyperactivity disorder (ADHD) and autism spectrum disease (ASD), growth, cardiovascular function, diabetes type 1, asthma, malignancies, and reproductive health.

\section{Neurodevelopmental health}

\section{Psychomotor and language development, behaviour, and social functioning}

Three SRs from the Netherlands, Denmark, and Australia described no differences in psychomotor development, overall social functioning, language development, and behaviour between children born after ART and spontaneously conceived controls (1-3).

\section{Cognitive development}

A recent SR focussing on cognitive development following ART (4) found conflicting results, mainly due to methodological limitations. However, three studies were considered high-quality studies and suggested ART to have some negative influence on cognitive development (5-7). In the early study by Strömberg and co-workers (5) including 5,680 children born after IVF (both singletons and multiples), a 4-fold increase in risk of developmental delay was observed as well as an increased risk of needing habilitation services compared with children from spontaneous conception. When comparing only singletons, there was no increased risk. In a Dutch study with a limited number of ART children, singletons from intracytoplasmic sperm injection (ICSI) were shown to have lower scores on tests of intelligence (on average 5-7 IQ points lower) compared with spontaneously conceived singletons (6). In a large population-based registry study ( $n=30,959$ ART children) from Sweden a small but significantly increased risk of mental retardation was found in ART children (relative risk [RR] 1.18, 95\% Cl 1.01-1.36) (7). When restricting analysis to singletons statistical significance disappeared. Further, in a subgroup analysis of singletons after frozen/thawed ICSI, there was an increased risk of mental retardation; however, this was based on few children $(n=7)$. A Danish registry study reported comparable risk of mental

CONTACT Christina Bergh christina.bergh@vgregion.se Department of Obstetrics and Gynecology, Institute of Clinical Sciences, Sahlgrenska Academy, Gothenburg University; Reproductive Medicine, Sahlgrenska University Hospital, Gothenburg SE-413 45, Sweden

(C) 2020 The Author(s). Published by Informa UK Limited, trading as Taylor \& Francis Group.

This is an Open Access article distributed under the terms of the Creative Commons Attribution License (http://creativecommons.org/licenses/by/4.0/), which permits unrestricted use, distribution, and reproduction in any medium, provided the original work is properly cited. 
retardation in IVF-conceived and spontaneously conceived singletons (8).

Recently, large registry-based studies from Sweden and Denmark have shown similar school performances of ART children and children born from spontaneous conception. The Swedish study (9) included 8,323 ART singletons compared with 1,499,667 children born after spontaneous conception, representing all ART and spontaneously conceived children born in Sweden between 1985 and 2001. Interestingly, the mean scores were around 10\% higher for the ART children. However, after adjustment for relevant confounders, results were similar in the two groups. Comparisons have also been made between children from IVF and ICSI and between children from fresh and frozen cycles (10-12), with similar results.

\section{Attention deficit hyperactivity disorder and autism spectrum disease}

ADHD was found to be weakly associated with IVF in a Swedish study including 28,158 multiples and singletons born after IVF. Yet after adjusting for length of involuntary childlessness, or when only singletons were analyzed, the statistical significance disappeared (13). A Danish study including 124,269 children born to women with fertility problems reported a higher risk of ADHD (hazard ratio [HR] 1.36, 95\% Cl 1.29-1.45) in these children compared with children born to women without fertility problems. No adjustment was made for multiple gestations in that study (14).

In a Swedish study, including 30,959 children born after ART, no increased risk of ASD was found compared to children born after spontaneous conception (7). Nor was there an increase in any emotional and behavioural disorder in a large Danish study (8). However, in a Californian cohort study a higher risk of ASD was reported in ICSI singletons compared with standard IVF with fresh embryo transfer (ET) (adjusted hazard risk ratio [aHR] 1.65, 95\% Cl 1.08-2.52) (ART $n=19,790$ ) (15). No comparison between children from ART and spontaneous conception was performed in that study (15). In a recent meta-analysis it was concluded that ART was associated with a greater risk of ASD in an overall offspring group compared with spontaneously conceived children (RR 1.35 , 95\% Cl 1.09-1.68); however, this was not seen in singletons (16).

\section{Cerebral palsy (CP)}

An increased risk of CP was found for singletons in an early Swedish study including 5,680 children born after IVF (aOR 2.8, 95\% Cl 1.3-5.8) (5). In a later and larger Swedish study, including 31,614 children born after IVF (multiples and singletons), born 1982-2007, there was a higher risk for CP when analysing singletons and multiple birth children together and compared with all children born during the same time period and registered in the Medical Birth Registry (aOR 1.81, 95\% Cl 1.52-2.13). The analysis was based on 138 ART children with $\mathrm{CP}$, and adjustments were made for maternal age, year of birth, parity, and smoking. When only singletons were analysed, no significant increased risk was found (17). Likewise, in a Danish study there was an increased risk for CP among 33,139 IVF children, but this disappeared when adjusted for multiplicity and gestational age (18). Another registry-based Danish study, however, including 10,329 singletons after fresh cycles and a control group of 4,800 spontaneously conceived singletons randomly selected, proved an increased risk of CP in singletons after fresh transfer (based on 42 CP cases) compared with spontaneously conceived singletons (aOR 2.44, 95\% Cl 1.15-5.22) (19). However, no adjustment was made for gestational age. In a recent Australian register study including a limited number of children $(n=2,914)$ born after ART, the prevalence of CP was more than doubled in ART singletons born very preterm ( $<32$ gestational weeks) (20) .

In summary, for most neurodevelopmental health variables conflicting results exist concerning a possible association between ART and adverse outcome. Most of the identified risk associations disappeared after adjustment for multiple births or were observed only in subgroups of specific IVF treatments such as cryopreservation. For $\mathrm{CP}$, in particular, there is a need of further large studies, including more recent cohorts of ART children.

\section{Cardiovascular function and metabolism}

The literature on cardiovascular and metabolic risks in ART offspring is limited. Studies published so far are based on small cohorts with high risk for selection bias among both ART children and controls. Cardiovascular and metabolic diseases mainly affect adults, while adolescents and young adults conceived after ART are not very common in registries covering these diseases.

The most recent SR and meta-analysis on cardiovascular diseases included 19 studies with 2,112 IVF/ICSI and 4,096 spontaneously conceived offspring (21). It was found that systolic blood pressure (SBP) and diastolic BP (DBP) levels were higher after ART than in spontaneously conceived offspring (weighted mean differences [WMD] 1.88, 95\% Cl 0.27-3.49 for SBP; and 1.51, 95\% Cl 0.33-2.70 for DBP). However, the higher WMD in SBP and DBP was only observed in the cohorts born 1990-1999 and not for children born later.

The same meta-analysis showed comparable body mass index (BMI), low-density lipoprotein, cholesterol, and fasting insulin levels for ART and spontaneously conceived children.

A Swiss study examined 65 ART singletons and 57 spontaneously conceived controls at 11-12 years of age and demonstrated adverse vascular dysfunction among ART children (22). These differences still existed at re-examination 5 years later when the children were 16-17 years old. Further, the ART children had significantly higher SBP and DBP (23).

In summary, limited data suggest a potential increase in blood pressure in ART children as well as suboptimal cardiovascular function. 


\section{Diabetes type 1}

Few studies have been published concerning the risk of developing diabetes type 1 in children conceived by ART. According to a Danish cohort study from 2016, including 8,490 IVF and ICSI children, there was no increased risk of diabetes type 1 (24). In a recent large registry study from Sweden, including 47,938 ART singletons and 3,090,602 singletons from spontaneous conception, there were 202 children born after ART that developed diabetes type 1 (25). The corresponding figure for children born after spontaneous conception was 17,916 . This corresponds to 43.4 (ART) and 35.5 (spontaneous conception) children when calculated per 100,000 person-years. After adjustment for several confounders, including maternal and paternal diabetes, there was no overall difference between ART and spontaneous conception (aHR 1.07, 95\% Cl 0.93-1.23). However, children conceived after frozen/thawed transfers had a higher risk of developing diabetes type 1, both compared with singletons from fresh transfers and children from spontaneous conceptions (aHR 1.52, 95\% Cl 1.08-2.14; and aHR 1.41, 95\% Cl 1.05-1.89).

In summary, information on the occurrence of diabetes type 1 in ART children is scarce. In general, there are no alarming results for ART children, although there might be an increased risk for children born after frozen/ thawed cycles.

\section{Growth}

Though children born after ART are more likely to be born preterm and with low birth weight, catch-up is common during the first year of life, and most studies have shown similar growth patterns in ART and children spontaneously conceived. In a recent SR and meta-analysis from Denmark (26), weight and height of ART singletons compared with spontaneously conceived singletons were summarized. The SR included 20 studies, altogether 3,972 ART children and 11,012 spontaneously conceived children, followed up for a maximum of 22 years. There were no significant differences in weight or height.

In summary, so far, overall results on growth in children born after ART suggest that they do not differ from spontaneously conceived children.

\section{Respiratory disorders}

Few studies have investigated the risk of asthma in ART children. A Swedish registry study of 2,628,728 children born in 1982-2007 including 31,918 children conceived by ART revealed an increased risk for asthma in children born after ART, increasing the absolute risk from $4.4 \%$ to $5.6 \%$ (27). However, adjustment for the duration of infertility eliminated the effect, suggesting that the main risk factor seemed to be subfertility, included in the characteristics of women in ART. A UK prospective study, the Millennium Cohort Study, of 18,818 singletons born after spontaneous conception or different kinds of fertility treatment, recruited at 9 months of age and based on a follow-up survey at 5 and 7 years of age, found a significant association between ART and asthma; however, this was based on few children after ART (28).

In summary, limited data suggest that the main risk factor for the association between asthma and ART is parental subfertility, but neonatal morbidity and maternal asthma may act as mediators.

\section{Malignancies}

A population-based British cohort study from 2013, including 106,013 ART children followed for a mean of 6.6 years, proved no increase in the overall risk of cancer when compared with the expected risk for singleton births (standardized incidence ratio [SIR] 0.98, 95\% Cl 0.81-1.19) (29). Another large registry-based cohort study, combining data from four Nordic countries (CoNARTaS, Committee of Nordic ART and Safety) including 91,796 children (singletons and multiples) born after ART and 358,419 children born after spontaneous conception, also concluded that there was no increase in overall cancer rates among ART children (aHR $1.08,95 \% \mathrm{Cl} 0.91-1.27$ ) (30). Children in this cohort were born 1982-2007 and were followed for a mean of 9.5 years. In a large cohort study from the United States, published in 2019, 275,686 children born after ART and 2,266,847 children born after spontaneous conception were followed for 4.5 and 4.7 years, respectively (31). Per 1,000,000 person-years the incidence of cancer among ART was 251.9 cases and among spontaneously conceived children 192.7 cases. In total 321 and 2,042 children with cancer were identified among ART and spontaneously conceived children, respectively (aHR 1.17, 95\% Cl 1.00-1.36). While no overall significant increase in cancer was observed, there was an increase of hepatic cancer and embryonal tumours among ART children in two sub-analyses. A recent study from the Netherlands, including 24,268 ART children and 13,761 children from spontaneous conceptions, but also including a control group of 9,660 children from subfertile couples, did not observe any increase in risk of cancer among the ART children (32). The study period was between 1980 and 2001, and the children were followed for a mean of 21 years. More recently, a study from Denmark, including 1,085,172 children born between 1996 and 2012 and followed up to 2015, investigated a possible association between use of fertility drugs, assisted reproduction, and cancer in childhood (33). The study included 19,448 IVF, 13,427 ICSI, and 3,356 children from cryopreservation, and a control group of 910,291 children born to fertile women. The mean follow-up was 11.3 years. No overall risk of cancer was found among children born to women with any fertility problems, any fertility treatment, use of any fertility drugs, or use of any ART. However, an increased risk was observed among children born after cryopreservation of embryos (aHR 2.43, 95\% Cl 1.44-4.1). This observation was, however, based on only 14 cases.

In summary, there is some inconsistency concerning malignancies in children conceived by ART. Higher risks have mainly been observed in subgroups of patients and for specific types of malignancies. 
Table 1. Summary of associations between ART and children's health and morbidity (versus spontaneous conception).

\begin{tabular}{|c|c|c|c|c|c|}
\hline \multirow[b]{2}{*}{ Disorder } & \multicolumn{2}{|c|}{ ART } & \multirow{2}{*}{ IVF } & \multirow{2}{*}{ ICSI } & \multirow{2}{*}{ Cryopreservation } \\
\hline & general & singletons & & & \\
\hline $\begin{array}{l}\text { Psychomotor and language } \\
\text { development, behaviour, and social } \\
\text { functioning }\end{array}$ & No association & No association & & & \\
\hline Cognitive development & & No association & No association & No association & No association \\
\hline ADHD and ASD & Increased risk & No association & & & \\
\hline Cerebral palsy & Increased risk & Conflicting results & & & \\
\hline Cardiovascular function, blood pressure & & Increased risk & & & \\
\hline Diabetes type 1 & & No association & No association & No association & Increased risk \\
\hline Growth & & No association & & & \\
\hline Asthma & No association & & & & \\
\hline Childhood malignancies & Conflicting results & No association & & & Increased risk \\
\hline Reproductive health & & & & $\begin{array}{l}\text { Some sperm problems } \\
\text { in men, no problems } \\
\text { in women }\end{array}$ & \\
\hline
\end{tabular}

\section{Reproductive health}

Researchers from Brussels have published the first studies on the reproductive outcome in ART offspring. In one study among 54 young adult men conceived by ICSI because of severe male infertility, it was found that sperm parameters were significantly lower in ART men than in men after spontaneous conception. There was, however, no clear correlation between semen parameters of the young ICSI men and their fathers (34). The same authors showed similar levels of reproductive hormones among ART and spontaneously conceived men, and also similar levels of reproductive hormones, antral follicle count, and levels of anti-Müllerian hormone in women conceived after ICSI $(35,36)$.

In summary, limited data published on reproductive health in ART offspring suggest some deterioration in sperm counts in ICSI male offspring, while in female offspring no adverse effects have been identified.

\section{Comments and conclusions}

Follow-up studies of children born after ART have shown that the majority of children are healthy, even though some adverse outcomes have been demonstrated (Table 1). The main risk for adverse outcomes in ART, which includes ICSI and standard IVF techniques as well as cryopreservation techniques, has been associated with the higher rates of multiple pregnancies in ART. Sweden has been the pioneering country in the world concerning introduction of single embryo transfer as the main strategy to increase the health of children born after ART (see www.qivf.se) (37).

Concerning long-term effects of ART on children outcomes, few studies of high quality exist. Studies of growth seem reassuring. For childhood cancer, some discrepancies exist, but most large studies do not show any increase in childhood cancer in ART children after adjustment for relevant confounders. Most studies on neurocognitive development and ASD show no increased risks if adjusted for multiple births. School performances of 15-16-year-old adolescents have been investigated in large registry studies from Denmark and Sweden and have shown better school performance for ART children in crude analyses, but after adjustment for relevant confounders, particularly parental education, no differences of clinical importance have been observed. There are some recent concerns regarding cardiovascular parameters. Cohort studies with a limited number of children included have detected altered blood vessel structure and increased blood pressure, both SBP and DBP, in ART singletons compared with matched controls and further that these differences remain in adolescence. For diabetes type 1, in a recent Swedish large registry study, there was no increase in general for ART children but a higher risk in children born after the use of cryopreserved embryos.

An important bias in all these follow-up studies is the choice of control group, being children from the general population in most studies. It is known that infertility per se is associated with an adverse child outcome, which may well contribute to the findings of a poorer outcome among ART children. Control groups with subfertile couples are, however, difficult to find. Sibling studies $(38,39)$, where the mothers have given birth to both an ART and a spontaneously conceived child suggest that both the infertility and the ART technique as such contribute to the child outcome.

In conclusion, even though many studies on follow-up of ART children show reassuring results, information on longterm follow-up is limited. New and advanced techniques are rapidly introduced and implemented, emphasising the importance of continuous surveillance of children born after ART.

\section{Disclosure statement}

No potential conflict of interest was reported by the author(s).

\section{Funding}

The study was financed by grants from the Swedish state under the agreement between the Swedish government and the county councils, the ALF-agreement [ALFGBG-70940].

\section{Notes on contributors}

Christina Bergh is Professor in Obstetrics and Gynaecology at the Department of Obstetrics and Gynaecology, Institute of Clinical Sciences, Gothenburg University. 
Ulla-Britt Wennerholm is Associate Professor in Obstetrics and Gynaecology at Sahlgrenska University Hospital.

\section{References}

1. Middelburg KJ, Heineman MJ, Bos AF. Hadders-Algra M. Neuromotor, cognitive, language and behavioural outcome in children born following IVF or ICSI-a systematic review. Hum Reprod Update. 2008;14:219-31. doi:10.1093/humupd/dmn005

2. Bay B, Mortensen EL, Kesmodel US. Assisted reproduction and child neurodevelopmental outcomes: a systematic review. Fertil Steril. 2013;100:844-53. doi:10.1016/j.fertnstert.2013.05.034

3. Hart R, Norman RJ. The longer-term health outcomes for children born as a result of IVF treatment. Part II-Mental health and development outcomes. Hum Reprod Update. 2013;19:244-50. doi:10. 1093/humupd/dmt002

4. Rumbold AR, Moore VM, Whitrow MJ, Oswald TK, Moran LJ, Fernandez RC, et al. The impact of specific fertility treatments on cognitive development in childhood and adolescence: a systematic review. Hum Reprod. 2017;32:1489-507. doi:10.1093/humrep/ dex085

5. Stromberg B, Dahlquist G, Ericson A, Finnstrom O, Koster $M$, Stjernqvist K. Neurological sequelae in children born after in-vitro fertilisation: a population-based study. Lancet 2002;359:461-5. doi: 10.1016/S0140-6736(02)07674-2

6. Knoester M, Helmerhorst FM, Vandenbroucke JP, van der Westerlaken LA, Walther FJ, Veen S, et al. Cognitive development of singletons born after intracytoplasmic sperm injection compared with in vitro fertilization and natural conception. Fertil Steril. 2008;90:289-96. doi:10.1016/j.fertnstert.2007.06.090

7. Sandin S, Nygren KG, lliadou A, Hultman CM, Reichenberg A. Autism and mental retardation among offspring born after in vitro fertilization. JAMA 2013;310:75-84. doi:10.1001/jama.2013.7222

8. Bay B, Mortensen EL, Hvidtjorn D, Kesmodel US. Fertility treatment and risk of childhood and adolescent mental disorders: register based cohort study. BMJ 2013;347:f3978-f3978. doi:10.1136/bmj. f3978

9. Norrman E, Petzold M, Bergh C, Wennerholm UB. School performance in singletons born after assisted reproductive technology. Hum Reprod. 2018;33:1948-59. doi:10.1093/humrep/dey273

10. Spangmose AL, Malchau SS, Schmidt L, Vassard D, Rasmussen S, Loft $A$, et al. Academic performance in adolescents born after ART-a nationwide registry-based cohort study. Hum Reprod. 2017; 32:447-56. doi:10.1093/humrep/dew334

11. Norrman E, Petzold M, Bergh C, Wennerholm UB. School performance in children born after intracytoplasmic sperm injection (ICSI). Hum Reprod 2020;318:PMC27781.

12. Spangmose $A L$, Malchau $S S$, Henningsen AA, Forman $J$ Rasmussen S, Loft $A$, et al. Academic performance in adolescents aged 15-16 years born after frozen embryo transfer compared with fresh embryo transfer: a nationwide registry-based cohort study. BJOG. 2019;126:261-9. doi:10.1111/1471-0528.15484

13. Kallen AJ, Finnstrom OO, Lindam AP, Nilsson EM, Nygren KG. Otterblad Olausson PM. Is there an increased risk for drug treated attention deficit/hyperactivity disorder in children born after in vitro fertilization? Eur J Paediatr Neurol. 2011;15;247-53. doi:10. 1016/j.ejpn.2010.12.004

14. Svahn MF, Hargreave M, Nielsen TS, Plessen KJ, Jensen SM, Kjaer SK, et al. Mental disorders in childhood and young adulthood among children born to women with fertility problems. Hum Reprod. 2015;30:2129-37. doi:10.1093/humrep/dev172

15. Kissin DM, Zhang Y, Boulet SL, Fountain C, Bearman P, Schieve L, et al. Association of assisted reproductive technology (ART) treatment and parental infertility diagnosis with autism in ART-conceived children. Hum Reprod. 2015;30:454-65. doi:10.1093/ humrep/deu338

16. Liu L, Gao J, He X, Cai Y, Wang L, Fan X. Association between assisted reproductive technology and the risk of autism spectrum disorders in the offspring: a meta-analysis. Sci Rep. 2017;7:46207. doi:10.1038/srep46207

17. Kallen B, Finnstrom $O$, Lindam AP, Nilsson EME, Nygren $K G$, Olausson PO. Cerebral palsy in children born after in vitro fertilization. Is the risk decreasing? Eur J Paediatric Neurol. 2010;14: 526-30. doi:10.1016/j.ejpn.2010.03.007

18. Hvidtjorn D, Grove J, Schendel D, Svaerke C, Schieve LA, Uldall P, et al. Multiplicity and early gestational age contribute to an increased risk of cerebral palsy from assisted conception: a population-based cohort study. Hum Reprod. 2010;25:2115-23. doi:10. 1093/humrep/deq070

19. Pinborg A, Loft A, Aaris Henningsen AK, Rasmussen S, Andersen AN. Infant outcome of 957 singletons born after frozen embryo replacement: the Danish National Cohort Study 1995-2006. Fertil Steril. 2010;94:1320-7. doi:10.1016/j.fertnstert.2009.05.091

20. Goldsmith S, Mclntyre S, Badawi N, Hansen M. Cerebral palsy after assisted reproductive technology: a cohort study. Dev Med Child Neurol. 2018;60:73-80. doi:10.1111/dmcn.13577

21. Guo XY, Liu XM, Jin L, Wang TT, Ullah $K$, Sheng JZ, et al. Cardiovascular and metabolic profiles of offspring conceived by assisted reproductive technologies: a systematic review and metaanalysis. Fertil Steril. 2017;107:622-31.e625. doi:10.1016/j.fertnstert. 2016.12.007

22. Scherrer U, Rexhaj E, Allemann Y, Sartori C, Rimoldi SF. Cardiovascular dysfunction in children conceived by assisted reproductive technologies. Eur Heart J. 2015;36:1583-9. doi:10. 1093/eurheartj/ehv145

23. Meister TA, Rimoldi SF, Soria R, von Arx R, Messerli FH, Sartori C, et al. Association of assisted reproductive technologies with arterial hypertension during adolescence. J Am Coll Cardiol. 2018;72: 1267-74. doi:10.1016/j.jacc.2018.06.060

24. Kettner LO, Matthiesen NB, Ramlau-Hansen CH, Kesmodel US, Bay B, Henriksen TB. Fertility treatment and childhood type 1 diabetes mellitus: a nationwide cohort study of 565,116 live births. Fertil Steril. 2016;106:1751-6. doi:10.1016/j.fertnstert.2016.09.009

25. Norrman E, Petzold M, Clausen TD, Henningsen AK, Opdahl S, Pinborg $A$, et al. Type 1 diabetes in children born after assisted reproductive technology: a register-based national cohort study. Hum Reprod. 2020;35:221-31. doi:10.1093/humrep/dez227

26. Bay B, Lyngsø J, Hohwu L, Kesmodel US. Childhood growth of singletons conceived following in vitro fertilisation or intracytoplasmic sperm injection: a systematic review and meta-analysis. BJOG. 2019;126:58-66. doi:10.1111/1471-0528.15456

27. Kallen B, Finnstrom O, Nygren KG. Otterblad Olausson P. Asthma in Swedish children conceived by in vitro fertilisation. Arch Dis Child 2013;98:2-6. doi:10.1136/archdischild-2012-301822

28. Carson C, Sacker A, Kelly Y, Redshaw M, Kurinczuk JJ, Quigley MA. Asthma in children born after infertility treatment: findings from the UK Millennium Cohort Study. Hum Reprod. 2013;28:471-9. doi: 10.1093/humrep/des398

29. Williams CL, Bunch KJ, Stiller CA, Murphy MF, Botting BJ, Wallace $\mathrm{WH}$, et al. Cancer risk among children born after assisted conception. N Engl J Med. 2013;369:1819-27. doi:10.1056/ NEJMoa1301675

30. Sundh KJ, Henningsen AK, Kallen K, Bergh C, Romundstad LB, Gissler $M$, et al. Cancer in children and young adults born after assisted reproductive technology: a Nordic cohort study from the Committee of Nordic ART and Safety (CoNARTaS). Hum Reprod. 2014;29:2050-7. doi:10.1093/humrep/deu143

31. Spector LG, Brown MB, Wantman E, Letterie GS, Toner JP, Doody $\mathrm{K}$, et al. Association of in vitro fertilization with childhood cancer in the United States. JAMA Pediatr. 2019;173:e190392. doi:10. 1001/jamapediatrics.2019.0392

32. Spaan $M$, van den Belt-Dusebout AW, van den Heuvel-Eibrink MM, Hauptmann M, Lambalk CB, Burger CW, et al. Risk of cancer in children and young adults conceived by assisted reproductive technology. Hum Reprod. 2019;34:740-50. doi:10.1093/humrep/ dey394

33. Hargreave $M$, Jensen $A$, Kjaer Hansen $M$, Dehlendorff $C$, Falck Winther J, Schmiegelow K, et al. Association between fertility 
treatment and cancer risk in children. JAMA. 2019;322:2203-10. doi:10.1001/jama.2019.18037

34. Belva $F$, Bonduelle $M$, Roelants $M$, Michielsen $D$, Van Steirteghem A, Verheyen G, et al. Semen quality of young adult ICSI offspring: the first results. Hum Reprod. 2016;31:2811-20. doi:10.1093/humrep/dew245

35. Belva F, Roelants M, De Schepper J, Van Steirteghem A, Tournaye $\mathrm{H}$, Bonduelle M. Reproductive hormones of ICSI-conceived young adult men: the first results. Hum Reprod. 2017;32:439-46. doi:10. 1093/humrep/dew324

36. Belva $F$, Roelants $M$, Vloeberghs V, Schiettecatte J, Evenepoel J, Bonduelle $M$, et al. Serum reproductive hormone levels and ultrasound findings in female offspring after intracytoplasmic sperm injection: first results. Fertil Steril. 2017;107:934-9. doi:10.1016/j. fertnstert.2017.02.102
37. Thurin A, Hausken J, Hillensjö T, Jablonowska B, Pinborg A, Strandell $A$, et al. Elective single-embryo transfer versus doubleembryo transfer in in vitro fertilization. N Engl J Med. 2004;351: 2392-402. doi:10.1056/NEJMoa041032

38. Romundstad LB, Romundstad PR, Sunde A, von During V, Skjaerven R, Gunnell D, et al. Effects of technology or maternal factors on perinatal outcome after assisted fertilisation: a population-based cohort study. Lancet 2008;372:737-43. doi:10.1016/ S0140-6736(08)61041-7

39. Henningsen AK, Pinborg A, Lidegaard $\varnothing$, Vestergaard C, Forman $\mathrm{JL}$, Andersen AN. Perinatal outcome of singleton siblings born after assisted reproductive technology and spontaneous conception: Danish national sibling-cohort study. Fertil Steril. 2011;95: 959-63. doi:10.1016/j.fertnstert.2010.07.1075 